\title{
CLASSIFYING CALCANEAL TENDON INJURY ACCORDING TO MRI FINDINGS
}

\author{
R. WEINSTABL, M. STISKAL, A. NEUHOLD, B. AAMLID, H. HERTZ
}

From University Clinic, Vienna

\begin{abstract}
Magnetic resonance imaging was performed on 28 patients with suspected calcaneal tendon injury prior to treatment. None of the patients were involved in competitive sports. All underwent clinical examination, some had had ultrasound or CT scans. We identified four types of lesions: type I, inflammatory reaction; type II, degenerative change; type III, incomplete rupture and type IV, complete rupture.

Thirteen of the 28 patients underwent surgery and the diagnostic findings were verified. We recommend that type I, type II and type III lesions be managed conservatively, while type IV lesions should be operated in the young and active patient.
\end{abstract}

Calcaneal tendon rupture can usually be diagnosed from the history and clinical examination (Ingliss et al 1976; Dederich et al 1988). In the past, conventional radiography with special soft-tissue techniques and xeroradiography have been the only methods to visualise the tendon defect. Thickening of the tendon, change in Karger's triangle or in the direction of the calcaneal tendon are all signs of rupture (Lehner et al 1987).

$\mathrm{CT}$ and ultrasound images can provide additional information but seldom sufficient for an exact diagnosis (Blei, Nirschl and Grant 1986). Complete rupture, partial rupture, stretch injury and tendonitis are all recognised diagnoses but no classification system exists to direct subsequent treatment. Since MRI has proved so useful in the diagnosis of other soft-tissue lesions, we have used it to classify calcaneal tendon disease (Reinig, Dorwart and Roden 1985; Ehman and Berquist 1986).

\section{PATIENTS AND METHODS}

The study group consisted of 28 patients ( 21 men, seven women). Their average age was 47.2 years (range 14 to

R. Weinstabl, MD, Orthopaedic Surgeon

H. Hertz, MD

University Clinic of Traumatology, Alserstrasse 4, A-1097 Vienna, Austria.

M. Stiskal, MD

A. Neuhold, MD

KH Rudolfinerhaus, Billrothstrasse 78, A-1190 Vienna, Austria.

B. Aamlid, MD, Chief Resident

Department of Orthopaedics, Mayo Clinic, Rochester, Minnesota 55905, USA

Correspondence should be sent to Dr R. Weinstabl.

(C) 1991 British Editorial Society of Bone and Joint Surgery $0301-620 X / 91 / 4199 \$ 2.00$

J Bone Joint Surg [Br] 1991 ; 73-B : 683-5.
82). Most had chronic pain and a history of injury. None of the patients took part in sporting activities at a highly competitive level. All underwent clinical examination followed by MRI; ultrasound examination was done in 11 cases and CT scans in four.

In eight cases there was a definite clinical diagnosis of complete rupture. In the other 20 patients the diagnosis was unclear. In 13 patients (eight men and five women) surgery verified the diagnosis.

In all cases spin-echo images at $5 \mathrm{~mm}$ thickness were obtained with a 0.5 Tesla Superconductive MR Unit (Phillips Gyroscan S5) using a $256 \times 256$ matrix. In 13 cases $T_{1}$ and $T_{2}$ weighted images were obtained in axial and sagittal planes $\left(T_{1}: T_{R} 450 / 550 \mathrm{msec}, T_{E} 30 \mathrm{msec}\right.$; $\left.T_{2}: T_{R} 2000 \mathrm{msec}, T_{E} 50 / 100 \mathrm{msec}\right) . T_{1}$ and gradient echo images, also in axial and sagittal planes $\left(\mathrm{GE}: \mathrm{T}_{\mathrm{R}} 555 \mathrm{msec}\right.$, $T_{E} 40$ msec, pulse angle 20) were obtained in 15 cases.

\section{RESULTS}

Because of its high water content, the normal calcaneal tendon is seen in all sequences as a dark band easily differentiated from the surrounding tissue. Its average width in the sagittal plane was 5 to $6 \mathrm{~mm}$ which correlates with the findings of Beltran et al (1987). In the transverse plane the tendon appears oval and in health it measures about $6 \mathrm{~mm}$ across, but the diameter is variable.

Based on MRI and operative findings we identified four categories of lesion.

Group I. Inflammatory reaction; thickening of the tendon without structural change of tendon tissue.

Of the 20 patients with an uncertain clinical diagnosis, seven showed thickening of the tendon to more than $6 \mathrm{~mm}$ in the anteroposterior diameter with no change of signal density in $T_{1}, T_{2}$ or gradient echo 


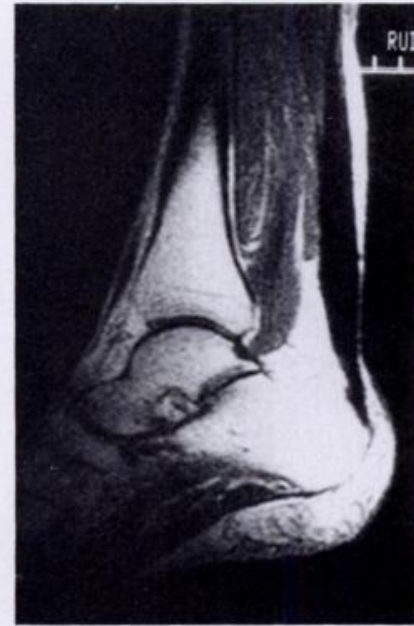

Fig. 1a

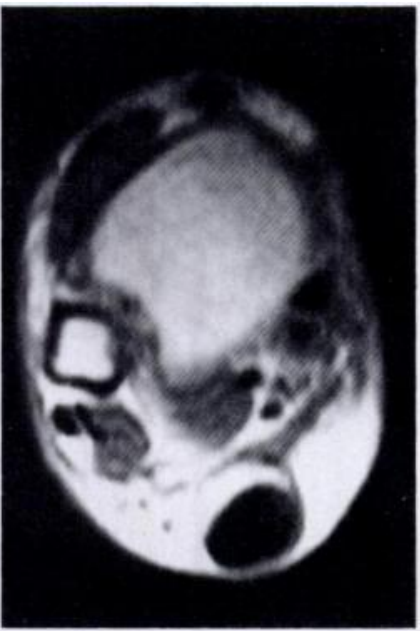

Fig. 1b

Figure 1a - T1 (550 : 30) sagittal plane. Thickening of the calcaneal tendon without structural change in the tendon tissue (group I). Figure 1b - T1 (550:30) transverse plane. The anteroposterior diameter measures more than $6 \mathrm{~mm}$.

images. Usually the maximal thickness occurred in the distal third of the tendon (Figs la,b).

Group II. Degenerative change; thickening of the tendon with longitudinally and centrally located image changes.

A further eight patients showed thickening of more than $6 \mathrm{~mm}$ in the anteroposterior diameter and had changes in signal intensity. The signal change was longitudinally oriented in the central portion of the tendon and did not reach to the surface (Figs 2a,b).

Group III. Incomplete rupture, thickening of the tendon with structural changes longitudinally and horizontally including the paratenon.

Five patients had anteroposterior thickening of the tendon, a change in signal intensity similar to group II and horizontally oriented areas of changed signal intensity which extended to the tendon surface and the paratenon. These findings were interpreted as showing incomplete or partial rupture. Four of these patients were

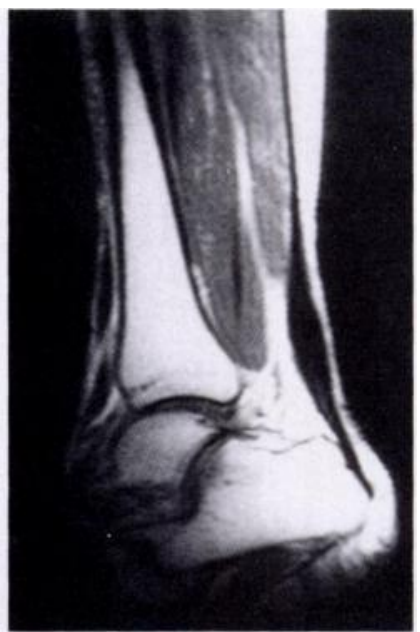

Fig. 2a

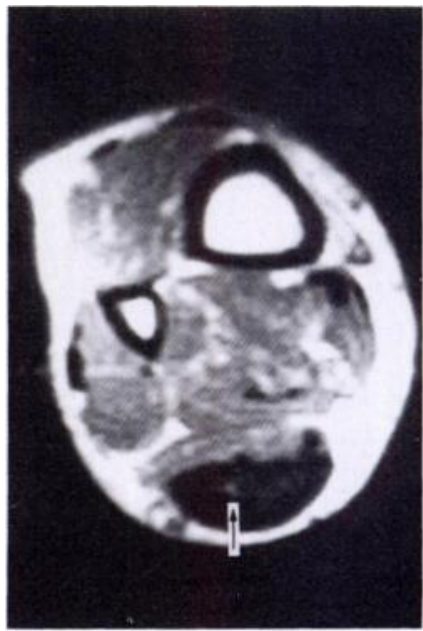

Fig. 2b
Figure $2 \mathrm{a}-\mathrm{T} 1(550: 30)$ sagittal plane. Thickening of the calcaneal tendon with central structural change (group II). Figure $2 b-T 1$ (550 30) transverse plane. The arrow points to the area of altered signal intensity.

treated operatively and all were found to have partial tendon tears with intact paratenon. Histology in two cases revealed degenerative change in the tendon and surrounding tissue (Figs 3a,b,c).

Group IV. Complete rupture.

Tendons with thickening of more than $6 \mathrm{~mm}$ in the anteroposterior plane with altered signal intensity and visible discontinuity of the tendon, presented three image variations:

a) Moderate signal-rich bands oriented perpendicular to the direction of the tendon fibres.

b) Signal-rich areas with hypo-intense borderline zones, on $T_{1}$ weighted images, in the fat in front of the tendon and in the haematoma surrounding it.

c) Thickening of the tendon with direct signs of rupture.

Toygar's angle was reduced in all cases from $150^{\circ}$ to about $135^{\circ}$ (Figs 4a,b).

Ultrasound investigations. Of the ten patients who had

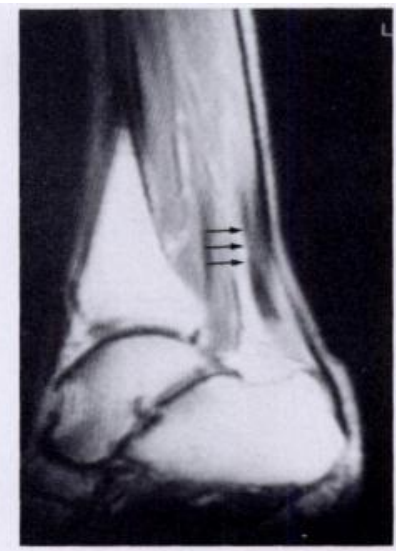

Fig. 3a

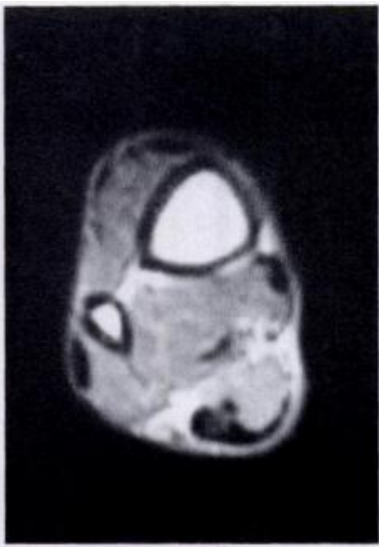

Fig. 3b

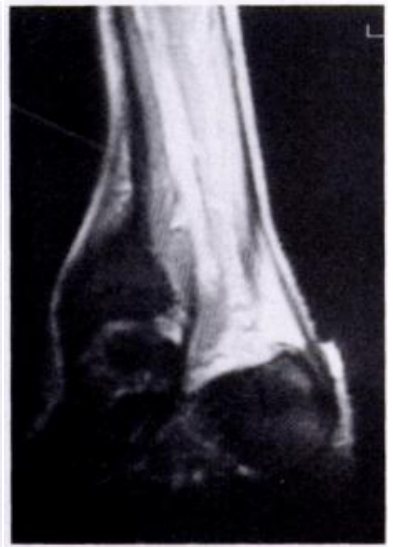

Fig. 3c
Figure $3 a-T 1(550: 30)$ sagittal plane. Incomplete calcaneal tendon rupture at the usual site. Figure $3 b-\mathrm{Tl}(550: 30)$ axial plane. Eccentric signal density (more than $50 \%$ of the normal tendon) connection to the paratendineal tissue. Figure 3c Gradient echo in the sagittal plane. 

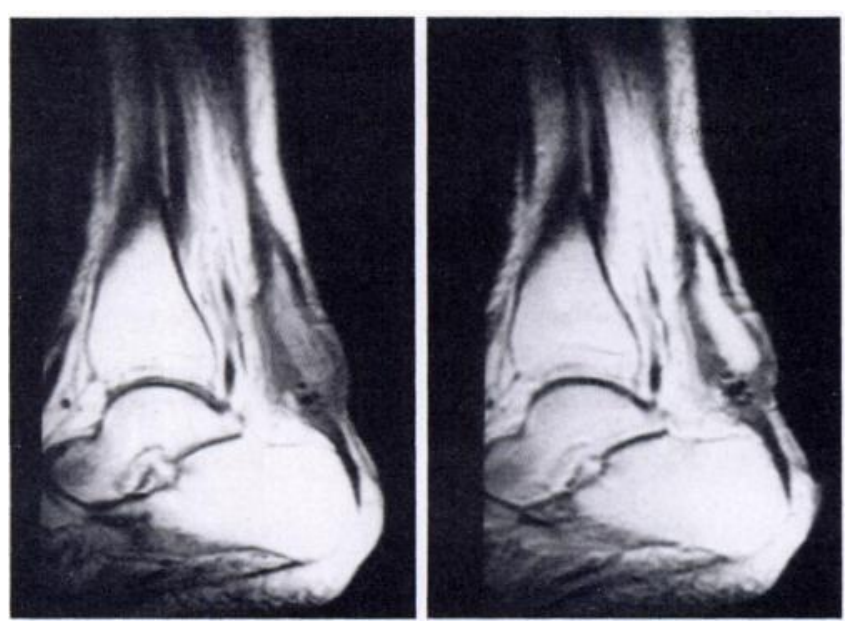

Fig. 4a

Fig.4b

Figure $4 \mathrm{a}-\mathrm{T} 1(550: 30)$ sagittal plane. High-signal intensity and visible discontinuity of the tendon. Figure $4 b-\mathrm{T} 2(1800: 100$. Increase of signal density - local oedema and haematoma in the area of the rupture.

ultrasound studies, one was in group I, four in group II, one in group III and four in group IV. One patient with an incomplete rupture had a false negative ultrasound evaluation but in the other cases the two investigations correlated.

CT scans. Two patients in group III had CT scans which could not be interpreted and two in group IV had CT scans which correlated with the MRI.
Clinical examination. Of the eight patients who were diagnosed clinically to have complete ruptures, one who was on steroid therapy for RA had bilateral simultaneous rupture. All these patients underwent surgical repair and the MRI findings were verified.

\section{CONCLUSION}

MRI is a helpful and accurate method to identify and classify achilles tendon lesions and can assist in directing treatment.

No benefits in any form have been received or will be received from a commercial party related directly or indirectly to the subject of this article.

\section{REFERENCES}

Beltran J, Noto AM, Herman LJ, Lubbers LM. Tendons: high-fieldstrength, surface coil MR imaging. Radiology 1987; 162:735-40.

Blei CL, Nirschl RP, Grant EG. Achilles tendon: US diagnosis of pathologic conditions. Radiology 1986; 159:765-7.

Dederich R, Bonse H, Hild A, Könn G, Wolf L. Achillessehnenrupturen. Ursachen - operationstechnik, ergebnisse, begutachtungsprobleme. Unfallchirurg 1988; $91: 259-69$ [Eng. Abstr].

Ehman RL, Berquist TH. Magnetic resonance imaging of musculoskeletal trauma. Radiol Clin North Am 1986; 24:291-319.

Ingliss AE, Scott WN, Sculco TP, Patterson AH. Ruptures of the tendo achilles. J Bone Joint Surg [Am] 1976; 58-A :990-3.

Lehner K, Reiser M, Paar O, Hawe W. Läsionen der achillessehne im MR-tomogramm. Roentgenpraxis 1987; 40:149-52.

Reinig JW, Dorwart RH, Roden WC. MR imaging of a ruptured achilles tendon. J Comput Assist Tomogr 1985; 9:1131-4. 